\title{
Myeloid-derived suppressor cells promote B-cell production of IgA in a TNFR2-dependent manner
}

\author{
Xia Xu1,6, Qinghong Meng1,2,6, Ulrike Erben ${ }^{3,6}$, Peigang Wang ${ }^{1}$, Rainer Glauben ${ }^{3}$, Anja A Kühl ${ }^{3}$, \\ Hao $\mathrm{Wu}^{1}$, Chung Wah Ma ${ }^{4}$, Minghua $\mathrm{Hu}^{4}$, Yuanyuan Wang ${ }^{4}$, Wei Sun ${ }^{5}$, Junying Jia ${ }^{1}$, Xinyi $\mathrm{Wu}^{1}$, \\ Wei Chen ${ }^{5}$, Britta Siegmund ${ }^{3}$ and Zhihai Qin ${ }^{1}$
}

\begin{abstract}
Myeloid-derived suppressor cells (MDSCs) are well known for their capacity to suppress antitumor T-cell responses, but their effects on B-cell function and antibody production remain unclear. Here, we found that MDSCs that accumulated around the germinal center in the spleen of tumor-bearing mice co-located with B cells. In the presence of MDSCs, the antibody reaction to a surrogate antigen was significantly enhanced in mice, especially the immunoglobulin (Ig)A subtype. Co-culture with MDSCs promoted both proliferation and differentiation of B cells into IgA-producing plasma cells in vitro. Interestingly, the cross talk between MDSCs and B cells required cell-cell contact. MDSCs from tumor necrosis factor receptor (TNFR) $2^{-I-}$ mice, but not from TNFR1 $1^{-I-}$ mice, failed to promote B-cell responses. Further investigation suggested that interleukin-10 and transforming growth factor- $\beta 1$ were crucial for the MDSC-mediated promotion of IgA responses. These results demonstrate a novel mechanism of MDSC-mediated immune regulation during tumor growth.

Cellular \& Molecular Immunology (2017) 14, 597-606; doi:10.1038/cmi.2015.103; published online 2 May 2016
\end{abstract}

Keywords: B cells; IgA; MDSCs; TNFR2

\section{INTRODUCTION}

Myeloid-derived suppressor cells (MDSCs), a heterogeneous population of cells that expand during cancer, inflammation and other pathological conditions, have been demonstrated to be important negative immune regulators. ${ }^{1}$ They accumulate around the germinal centers in the spleen of tumor-bearing mice $^{2,3}$ and are well known for their remarkable ability to suppress T-cell responses in the tumor microenvironment. ${ }^{4}$ Apart from MDSCs, B cells might also act as negative regulators for antitumor immunity. ${ }^{5}$ Although their presence is required in protective immunity against virus-induced tumors, ${ }^{6}$ there is growing evidence that in B-cell-deficient $\mu \mathrm{MT}$ mice, the tumors tend to be rejected, ${ }^{7}$ and adoptive transfer of $\mathrm{B}$ cells or serum can enhance squamous carcinogenesis. ${ }^{8}$ These results imply that B cells are beneficial rather than inhibitory to tumor development. Compared with the well-studied inhibition on T-cell responses by MDSCs, the effect of MDSCs on B-cell function remains unclear.

Immunoglobulin (Ig)A is well known for its prevalence in mucosal tissues and its role in mucosal immunity. ${ }^{9}$ However, it is also clear that a proportion of IgA is present in the serum and hence does not participate in mucosal immunity. ${ }^{10}$ The depletion of the intestinal microbiota causes deficiency in IgA production in the intestinal mucosa, but it has little effect on serum IgA levels. ${ }^{11}$ This result suggests that some serum IgA is produced independently of mucosal IgA through mechanisms that are unknown at present. We frequently observed that in spleens of tumor-bearing mice, $\operatorname{IgA}{ }^{+}$cells around the germinal centers become associated with MDSCs, prompting us to hypothesize that MDSCs might play a crucial role in the generation of $\mathrm{IgA}^{+}$cells and therefore the production of serum IgA.

\footnotetext{
${ }^{1}$ Key Laboratory of Protein and Peptide Pharmaceuticals, Chinese Academy of Sciences-University of Tokyo Joint Laboratory of Structural Virology and Immunology, Institute of Biophysics, Chinese Academy of Sciences, Beijing 100101, China; ${ }^{2}$ University of Chinese Academy of Sciences, Beijing 100049 , China; ${ }^{3}$ Medical Department for Gastroenterology, Infectious Diseases and Rheumatology/Research Center ImmunoSciences, Campus Benjamin Franklin, Charité-Universitätsmedizin Berlin, Berlin 12200, Germany; ${ }^{4}$ Infinitus Chinese Herbal Immunity Research Centre, Guangzhou 510665, China and ${ }^{5}$ Berlin Institute for Medical Systems Biology, Max Delbrück Center for Molecular Medicine Berlin-Buch, Berlin 13125, Germany

${ }^{6}$ These authors contributed equally to this work.

Correspondence: Dr ZH Qin, Key Laboratory of Protein and Peptide Pharmaceuticals, Chinese Academy of Sciences-University of Tokyo Joint Laboratory of Structural Virology and Immunology, Institute of Biophysics, Chinese Academy of Sciences, 15Datun Road, Beijing 100101, China.

E-mail: zhihai@ibp.ac.cn.
}

Received: 23 October 2015; Revised: 20 November 2015; Accepted: 20 November 2015 
Tumor necrosis factor (TNF) is an important inflammatory cytokine and is secreted by both tumor and stromal cells in the tumor microenvironment. ${ }^{12}$ The biological functions of TNF are mediated by two receptors, TNF receptor-1 (TNFR1) and TNFR2. TNFR1 is expressed universally on almost all cell types, whereas TNFR2 is restricted to immune cells. ${ }^{13}$ As their ligand, TNF is either integrated in the plasma membrane as memTNF, where it binds mainly to TNFR2, or proteolytically released as soluble TNF, which functions as the main ligand for TNFR1. ${ }^{14}$ Signaling pathways that are mediated by TNFR1 have been extensively studied. As for TNFR2, although it was previously shown to be involved in MDSC survival and activity, 3,15 knowledge is lacking regarding its function and signaling pathways.

In the present study, we revealed a novel dialog between MDSCs and B cells, which is mediated by memTNF on B cells and TNFR2 on MDSCs. MDSCs activated by memTNF promoted splenic B cells to produce IgA. Our results not only identify a role for MDSCs in humoral immune responses, hence influencing tumor growth, but also shed new light on the source of $\operatorname{IgA}^{+} \mathrm{B}$ cells, which have a crucial role for immunosuppression. ${ }^{16}$

\section{MATERIALS AND METHODS}

\section{Animals}

C57BL/6 mice were purchased from Weitonglihua Corporation (Beijing, China). TNFR1 ${ }^{-1-}$ mice of a mixed genetic background, including 129/Sv/Ev and C57BL/6, were kindly provided by Dr Horst Bluethmann (Hoffmann-La Roche, Basel, Switzerland). TNFR2 ${ }^{-l-}$ mice were obtained from Jackson Laboratory. Both strains of mice were backcrossed for 12 generations onto the C57BL/6 background, and female mice aged 6-8 weeks were used. All of the mice were maintained in a pathogen-free barrier facility at the Institute of Biophysics, Chinese Academy of Sciences. The animal experiments were carried out with the approval of the Institutional Laboratory Animal Care and Use Committee.

\section{Cell lines}

MCA205 fibrosarcoma cells are of the C57BL/6 origin. ${ }^{17}$ All of the cells were cultured in Roswell Park Memorial Institute (RPMI) 1640 medium that was supplemented with $10 \%$ fetal calf serum as described. ${ }^{3}$

\section{In vivo studies}

Tumors were induced as previously described. ${ }^{3}$ In brief, $5 \times 10^{5}$ MCA205 cells in $200 \mu \mathrm{l}$ phosphate-buffered saline (PBS) were injected subcutaneously. Then, the spleens were taken for in situ immunofluorescence and to isolate defined cell populations that were used in the in vitro experiments after 3 weeks. For induction of antibody production in mice, tumorbearing mice and tumor-free control mice received $100 \mu \mathrm{g}$ ovalbumin (OVA) protein that was dissolved in incomplete Freud's adjuvant. Part of the tumor-bearing mice group were treated with daily intraperitoneal injections of $0.4 \mathrm{mg} / \mathrm{g}$ alltrans retinoic acid (ATRA) for 20 days. ${ }^{18,19}$ After 14 days, all of the mice were challenged with $10 \mu \mathrm{g}$ OVA. The serum samples were retrieved for detection of the OVA-specific antibody subtypes. Chemicals were purchased from Sigma-Aldrich (St. Louis, MO, USA).

\section{Isolation and transfer of murine MDSCs}

$\mathrm{CD} 1 \mathrm{~b}^{+} \mathrm{Gr} 1^{+}$MDSCs were isolated using a FACS Aria II (BD Biosciences, San Jose, CA, USA), and freshly prepared MDSCs $\left(5 \times 10^{6}\right.$ in $100 \mu \mathrm{l}$ PBS) were transferred intravenously to wild-type mice as previously described. ${ }^{3}$ For the in situ immunofluorescence, spleens were retrieved and cryopreserved 2 days after MDSC transfer. For the antibody detection, MDSCs were intravenously transferred into naive wild-type mice where they could be traced within the spleen for 7 days. ${ }^{3}$ Two days later, these mice, and wild-type mice that did not receive MDSCs, were immunized with $100 \mu \mathrm{g}$ OVA. All of the mice were challenged with $10 \mu \mathrm{g}$ OVA 14 days later. Where applicable, MDSC transfer was repeated once weekly for 3 weeks. Serum samples were retrieved for detection of the OVA-specific antibody subtypes.

\section{In vitro culture of murine cells}

Non-adherent spleen cells from naive mice were cultured alone or co-cultured with MDSCs in the presence or absence of $1 \mu \mathrm{g} / \mathrm{ml}$ lipopolysaccharides (LPS), and the ratio of nonadherent spleen cells to MDSCs was 3:1.

Specific neutralizing antibodies were purchased from R\&D Systems (Minneapolis, MN, USA), including transforming growth factor (TGF)- $\beta$ (clone 1D11), TNFR1 (clone 55R170), interleukin (IL)-10 (clone JES052A5) and TNF (catalog number AF-410-NA); or from Biolegend (San Diego, CA, USA), including TNFR2 (clone TR75-54.7). The TGF $\beta$ receptor-1 (TGFßRI) kinase inhibitor, SD208 was from Tocris Bioscience (Bristol, UK).

Detection of the total and OVA-specific antibody subtypes Antibodies from sera or culture supernatants were assessed using an enzyme-linked immunosorbent assay (ELISA) for mouse antibody clonotyping (Southern Biotech, Birmingham, AL, USA). The total antibody amounts were quantified as the manufacturer's instructions. As for the OVA-specific antibodies, the capture antibody from the first step was replaced by $10 \mu \mathrm{g} / \mathrm{ml}$ OVA.

\section{Flow cytometry}

Single-cell suspensions that were prepared directly from spleens were stained with the following directly conjugated mousespecific monoclonal antibodies that were purchased from BD Pharmingen (San Diego, CA, USA), including CD4 (clone RM4-5), CD11b (clone M1/70), CD80 (clone 16-10A1), CD86 (clone GL1), TNFR2 (clone TR75-89), CD138 (clone 281-2) and IgA (clone C10-3); from Biolegend, including B220 (clone RA3-6B2), Gr1 (clone RB6-8C5), TNFR1 (clone 55R-286); or from eBioscience (San Diego, CA, USA), including TNFo (clone MP6-XT22). 
In situ immunofluorescence and confocal microscopy

In situ immunofluorescence from cryostat or paraffin tissue sections was performed as described previously. ${ }^{2}$ Spleen sections were stained with rat, rabbit or goat anti-mouse or human (Ki67) antibodies specific to B220 (clone RA3-6B2; BD Biosciences), CD11b (catalog number NB110-89474; Novus Biologicals, Littleton, CO, USA), Gr1 (clone RB6-8C5), IgA (clone C10-1; BD Biosciences), IgA (catalog number A90-103A; Bethyl Laboratories, Montgomery, TX, USA), or Ki67 (clone B56; BD Biosciences) followed by Alexa Fluor 488 donkey anti-rat, Alexa Fluor 555 donkey anti-rabbit, Alexa Fluor 555 donkey anti-goat, Alexa Fluor 555 goat anti-rat or Alexa Fluor 488 donkey anti-mouse IgG antibodies (Life Technologies, Carlsbad, CA, USA). The nuclei were counterstained with 4'-6-diamidino-2-phenylindole (DAPI) (SigmaAldrich). Primary antibodies were omitted for negative controls. The sections were visualized by fluorescence microscopy using a FV1000 confocal laser scanning microscope (Olympus, Tokyo, Japan) and a DP71 microscopic digital camera.

\section{Cytokine detection}

TGF- $\beta 1$ in the culture supernatants was detected with ELISA kits (R\&D Systems, Minneapolis, MN, USA). The IL-6, monocyte chemotactic protein (MCP)-1, interferon (IFN)- $\gamma$, TNF and IL-10 levels were assayed with a mouse inflammation cytometric bead array (CBA) kit (BD Pharmingen) and the data were analyzed using the CBA software.

\section{Statistical analysis}

The data were analyzed using the GraphPad Prism software (version 5; GraphPad Software, La Jolla, CA, USA). $P<0.05$, as determined by Mann-Whitney or Student's $t$-tests, were considered statistically significant.

\section{RESULTS}

\section{MDSCs co-localize with B cells in the spleens of} tumor-bearing mice

To investigate the local relationship of MDSCs to cells of the B-lymphatic lineage, we first evaluated the distribution of $\mathrm{CD}_{11} \mathrm{~b}^{+}$and $\mathrm{B} 220^{+}$cells in the spleen in situ using immunofluorescence (Figure 1a). Within the spleens of naive mice, the $\mathrm{CD}_{1} 1 \mathrm{~b}^{+}$cells were rare and mainly distributed within the marginal zone. In tumor-bearing mice, the number of CD $11 b^{+}$ cells was significantly increased. These cells were localized around the germinal centers and co-localized with the $\mathrm{B} 220^{+}$ marginal zone $\mathrm{B}$ cells. Most of these $\mathrm{CD}_{11 \mathrm{~b}}{ }^{+}$cells were also $\mathrm{Gr}^{+}$, as shown by flow cytometry (Figure $1 \mathrm{~b}$ ). The $\mathrm{CD}_{11 \mathrm{~b}^{+} \mathrm{Gr} 1^{+}}$cells that were isolated from the spleens of tumor-bearing mice had the capacity to inhibit T-cell proliferation and they had high arginase and inducible nitric oxide synthase activities (Supplementary Figure 1). Together, these results indicate that these cells were indeed MDSCs. Using in situ immunofluorescence (Figure 1c; Supplementary Figure 2) and flow cytometry (Figure 1d), we observed that significantly increased numbers of $\mathrm{B}^{2} 20^{-} \mathrm{IgA}^{+}$cells ${ }^{20}$ accumulated within the spleens of tumor-bearing compared with naive control mice. These IgA ${ }^{+}$cells within the spleens of the naive control and tumor-bearing mice were mostly outside of the germinal centers; however, they were only associated with $\mathrm{Gr}^{+}$ cells in the tumor-bearing mice (Figure 1e). These findings suggested that MDSCs interact closely not only with $\mathrm{B} 220^{+}$ $\mathrm{B}$ cells but also with $\mathrm{B} 220^{-} \mathrm{IgA}^{+}$cells, which were recruited into the spleen during tumor progression.

\section{MDSCs promote proliferation of marginal zone B cells and antibody production in vivo}

To investigate whether MDSCs modulate B-cell responses, we first tested how MDSCs affect the activation state of splenic B cells in vivo. Upon transfer of MDSCs and subsequent immunization with OVA as a surrogate antigen, hot spots of proliferation within the spleen appeared at the margin of the germinal centers within two days (Figure 2a). A substantial increase of $\mathrm{Ki}^{2} 7^{+} \mathrm{B} 220^{+}$cells was found adjacent to germinal centers in the mice that received purified MDSCs, but not in the control mice. Within 14 days, the OVA immunization in the presence of MDSCs significantly enhanced the production of OVA-specific IgG2b, but not the other Ig-subtypes (Supplementary Figure 3a; Figure 2b). Seven days after repeated encounter with OVA, only the IgA levels were significantly elevated in the presence of MDSCs compared with the controls (Figure 2b). These results suggest that MDSCs modulate antibody production by $\mathrm{B}$ cells upon local interaction.

Next, we assessed the effect of OVA immunization in an animal model that generated MDSCs within 20 days after transplantation of MCA205 cells. The influence of MDSCs was further verified by MDSC depletion with ATRA treatment, as reported previously. ${ }^{18,19}$ Except for IgG2a and IgG3, all of the OVA-specific antibody subtypes were significantly higher in the serum of the MCA205 tumor-bearing mice when compared with the tumor-free mice 14 days after OVA injection, and all of the effects were reversed with ATRA (Figure 2c; Supplementary Figure 3b). Remarkably, this was independent of tumor development or MDSC depletion in the tumorbearing mice that also received the OVA immunization (Figure 2c; Supplementary Figure 3b). However, only the IgA levels remained significantly different in the MDSC treated tumor-bearing mice compared with the control mice at 7 days after OVA challenge (Figure 2c). At this time point, the concentrations of all other antibody subtypes tested, including IgM and IgG, were comparable between the groups. Thus, the MDSC depletion not only prevented the induction of specific antibody subtypes, but also abolished the effect on systemic IgA production and pointed to a direct involvement of MDSCs in antibody class switching.

\section{MDSCs promote $\mathrm{B}$-cell responses in vitro}

To investigate the potential effect of MDSCs on B-cell development, isolated MDSCs were co-cultured with nonadherent spleen cell fractions containing B cells. LPS is a potent murine polyclonal B-cell activator, and has been widely adopted as a tool to study plasma cell differentiation 
in vitro. ${ }^{21}$ Using carboxyfluorescein succinimidyl ester, we found that LPS-induced B-cell proliferation, while MDSCs alone had no such effect. However, the combination of MDSCs and LPS induced significantly greater proliferation levels than LPS alone (Figure 3a). To investigate the effect of MDSCs on B-cell activation, we assessed the levels of co-stimulatory molecules on $\mathrm{B}_{2} 20^{+}$cells. Although LPS upregulated the expression of CD80 and CD86, the MDSCs alone had no such effect. Similarly, MDSCs and LPS significantly increased the expression levels of these co-stimulatory molecules on the surface of B cells, and the CD86 levels were upregulated the most (Figure 3b). Furthermore, the LPS alone treatment generated only low percentages of $\mathrm{B} 220^{-} \mathrm{CD} 138^{+}$differentiated plasma cells. However, the addition of the MDSCs alone treatment was nearly twice as effective as LPS (Figure 3c). However, the presence of LPS in combination with MDSCs significantly expanded the $\mathrm{B} 220^{-} \mathrm{CD} 138^{+}$population from $2 \%$ to about $8 \%$ (Figure 3c), suggesting that MDSCs play an important role in the terminal differentiation of activated $\mathrm{B}$ cells into plasma cells. To assess the capacity of $\mathrm{B} 220^{-} \mathrm{CD} 138^{+}$ cells to produce IgM and IgA in vitro, we tested IgM and IgA production in co-culture system. As Figure $3 \mathrm{~d}$ shows, LPS increased the levels of IgM independent of the presence of MDSCs. The MDSCs induced IgA production within the cultures. The addition of LPS to the B-cell and MDSC cultures significantly enhanced the effect of MDSCs on IgA production.
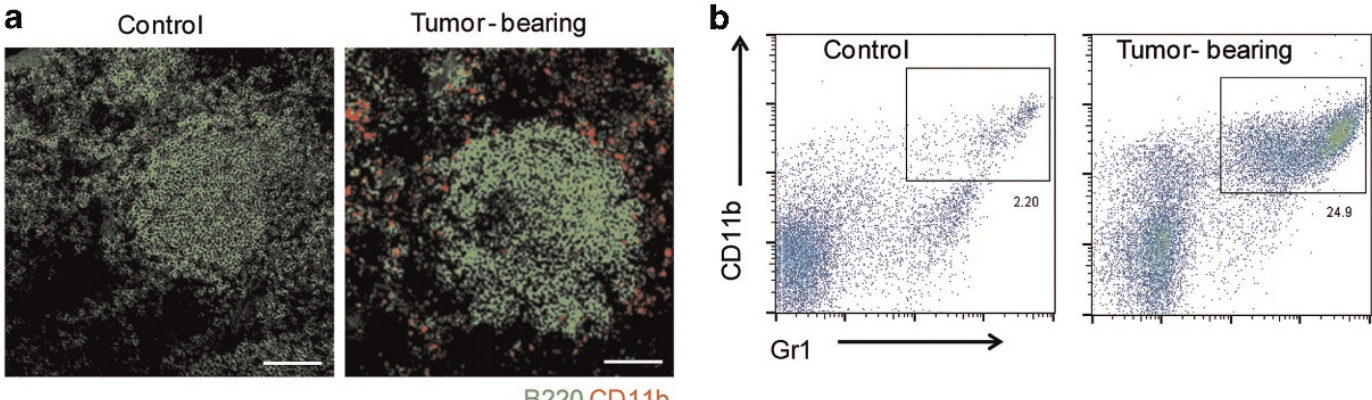

B220 CD11b
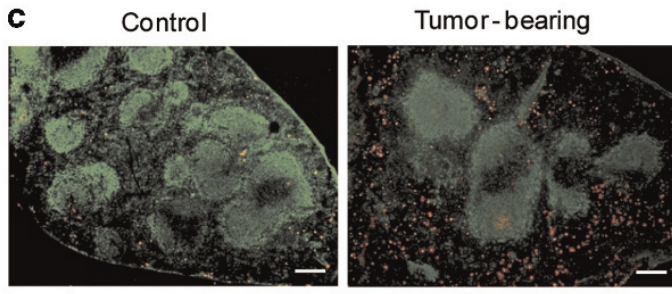

$B 220 \lg A$
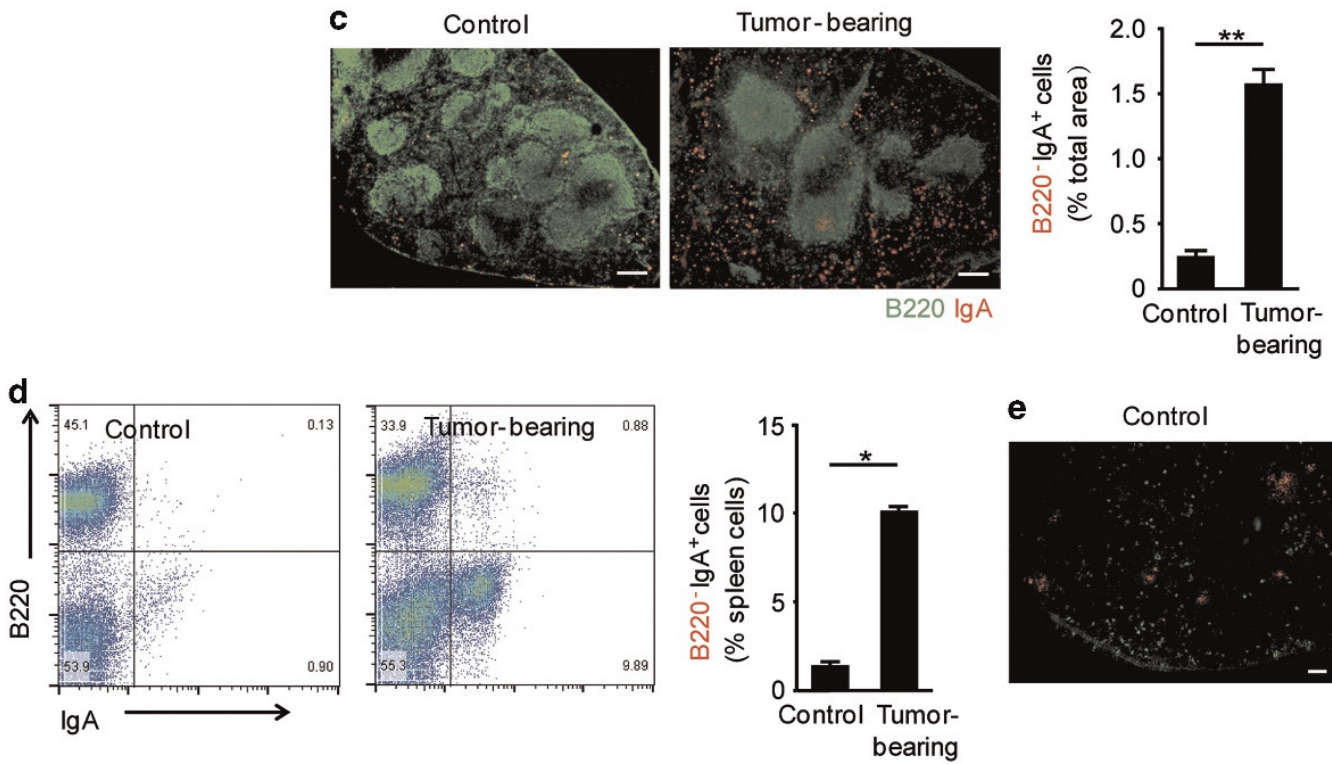

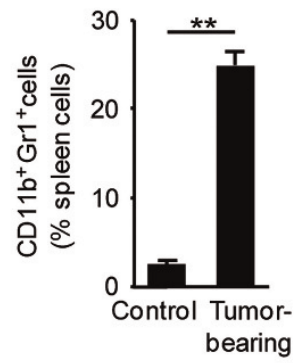

e
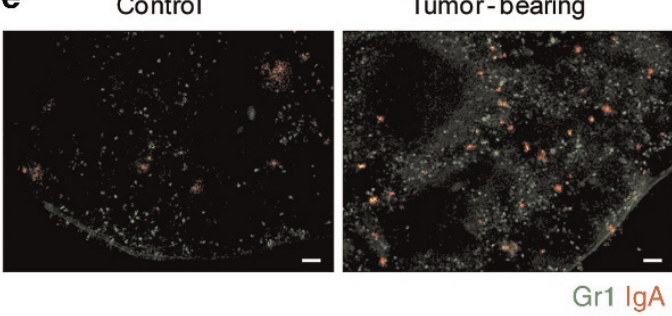

Figure 1 Close localization of MDSCs and B cells in the spleen. Tumors were induced in C57BL/6 wild-type mice by subcutaneously injecting MCA205 $\left(5 \times 10^{5}\right)$ tumor cells. Then, the spleens were studied after three weeks. Untreated mice served as controls. ${ }^{*} P<0.05$ and $* * P<0.01$, as determined with Student's t-test. (a) Spleen sections were stained for B220 (green) and CD11b (red) and were assessed by CLSM. The cLSM images are representative of three independent experiments with 3 mice per group; Scale bars, $100 \mu \mathrm{m}$. (b) Isolated splenocytes were stained for CD11b and Gr1, and the CD11 b $\mathrm{Gr}^{+}$cells were analyzed by flow cytometry. The percentages are indicated in the representative dot plots. The results are shown as the mean values \pm s.e.m. of the $C D 11 b^{+} G r 1^{+}$cell percentages from three independent experiments with 3 mice per group per experiment. (c) Spleen sections were stained for B220 (green) and IgA (red) and they were subsequently analyzed by fluorescence microscopy. The left panel shows representative images (scale bars, $200 \mu \mathrm{m})$ and the right panel indicates the mean values \pm s.e.m. of the B220-IgA+ cell percentages from three independent experiments with 2-3 mice per group. (d) Isolated splenocytes were stained for B220 and IgA, and the B220-IgA+ cells were analyzed by flow cytometry. The percentages are indicated in the representative dot plots. The results are shown as the mean values \pm s.e.m. of the B220 ${ }^{-}$IgA ${ }^{+}$cell percentages from three independent experiments with 3 mice per group per experiment. (e) Spleen sections that were stained for Gr1 (green) and IgA (red) were analyzed by fluorescence microscopy. The images are representative of two independent experiments with 3 mice per group; scale bars, $50 \mu \mathrm{m}$. cLSM, confocal laser scanning microscope; IgA, immunoglobulin A; MDSCs, myeloid-derived suppressor cells. 
The subtypes other than IgM and IgA were also tested, and IgG1 and IgG2b were also induced by the addition of the MDSCs (Supplementary Figure 4).

Taken together, MDSCs promoted B-cell activation and differentiation into IgA-producing plasma cells in vitro.

\section{TNFR2 expression is crucial for MDSC-induced B-cell} proliferation

TNF is essential for MDSC accumulation in tumor-bearing hosts. ${ }^{3}$ Here, we found that $\mathrm{CD}_{11} \mathrm{~b}^{+} \mathrm{Gr} 1^{+}$MDSCs from tumorbearing mice expressed TNFR1 and TNFR2 (Supplementary Figure 5a). Additionally, the percentages of $\mathrm{memTNF}^{+} \mathrm{B} 220^{+}$ $\mathrm{B}$ cells were significantly increased by more than twofold after $24 \mathrm{~h}$ of culture in the presence of MDSCs and LPS compared with each of the components alone (Supplementary Figure 5b). We therefore addressed the question as to whether TNF receptor expression has an impact on the interaction between B cells from wild type and MDSCs from TNFR $1^{-1-}$ and TNFR2 ${ }^{-1-}$ mice. Both for the TNFR1 $1^{-1-}$ and TNFR2 ${ }^{-1-}$ MDSCs, we observed that the effect of MDSCs on B-cell proliferation without LPS were comparable to that in the WT controls. However, upon the addition of LPS, B-cell proliferation in the presence of MDSCs was only observed in the $\mathrm{TNFR}^{-1-}$ mice (Figures 3a, 4a and b). Following immunofluorescence staining of adhered cells, we observed that the TNFR $1^{-/-}$MDSCs attached to B cells but not the TNFR2 ${ }^{-/-}$ MDSCs (Figure 4c). Additionally, B-cell proliferation and cell-cell contact with MDSCs were prevented with a TNFR2-specific blocking antibody (Figures $4 \mathrm{~d}$ and e).

On the basis of these results, we concluded that MDSCinduced B-cell proliferation required cell-cell contact via TNFR2. a
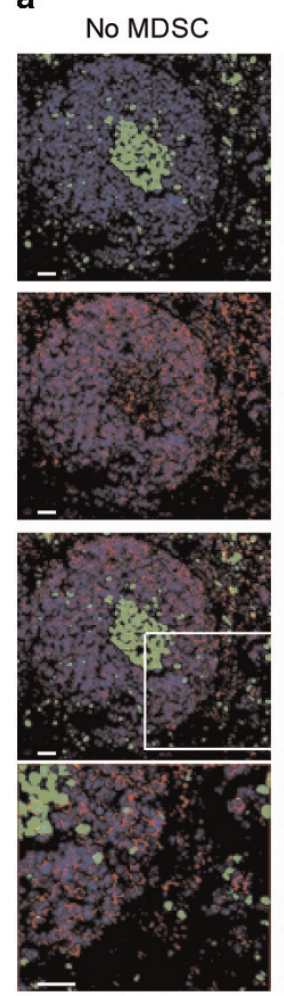

MDSC transfer
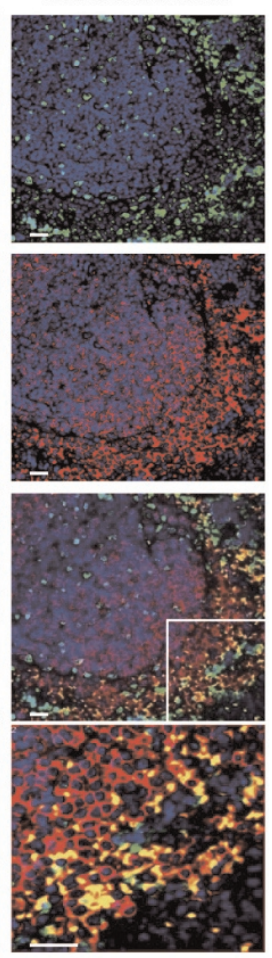

Ki67 B220 DAPI b
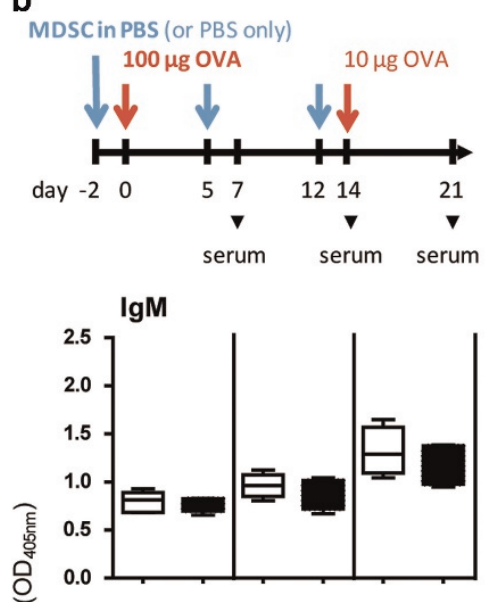

文 1.0

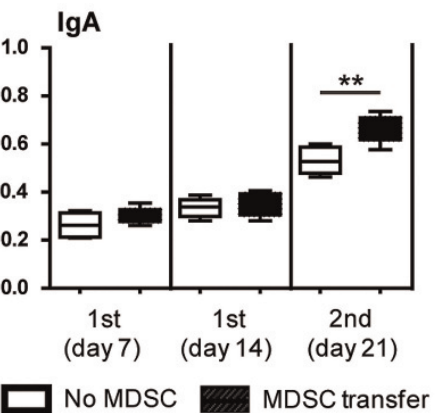

c
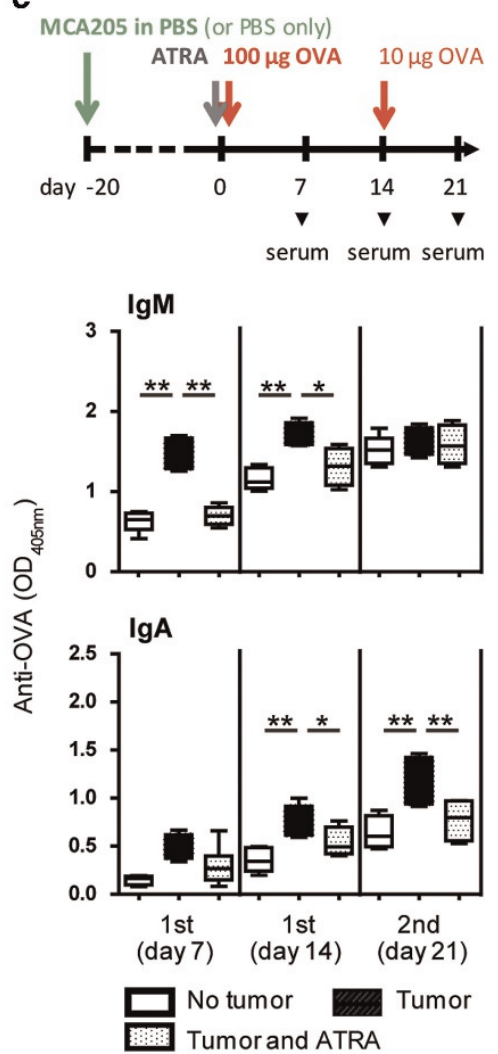

Figure 2 MDSCs promote B-cell proliferation and IgA production. (a) MDSCs $\left(5 \times 10^{6}\right)$ were intravenously transferred into naive wild-type mice. These mice and untreated wild-type mice were immunized with OVA (100 $\mu \mathrm{g})$. After 2 days, spleen sections were stained for Ki67 (green) and B220 (red). The nuclei were counterstained with DAPI (blue). The cLSM images are representative of two independent experiments with 2 mice per group. Original magnifications: 1st to 3rd rows. The bottom row shows an enlarged image of the marked area in the 3rd row: scale bars, $50 \mu \mathrm{m}$. (b) MDSCs $\left(5 \times 10^{6}\right)$ were intravenously transferred into naive wild-type mice. Two days later, these mice and wild-type mice that did not receive MDSCs were immunized with OVA (100 $\mu \mathrm{g})$. The MDSC transfer was repeated once weekly for 3 weeks. Each mouse was challenged with OVA $(10 \mu \mathrm{g}) 14$ days later. (c) Wild-type mice subcutaneously received MCA205 $\left(5 \times 10^{5}\right)$ tumor cells in PBS or PBS alone. After 20 days, half of the MCA205 tumor-bearing mice were treated with ATRA. The mice from all groups were immunized with OVA $(100 \mu \mathrm{g})$ and challenged with OVA $(10 \mu \mathrm{g}) 14$ days later. For b and c, the OVA-specific IgM and IgA antibody serum concentrations were assessed at day 7 and 14 during the primary immunization (1st) as well as 7 days after the challenge (2nd). Shown are representative results of two independent experiments with 8 mice per group. ${ }^{*} P<0.05$ and ${ }^{*} P<0.01$, as determined with the Mann-Whitney test. ATRA, all-trans retinoic acid; cLSM, confocal laser scanning microscope; Ig, immunoglobulin; MDSCs, myeloid-derived suppressor cells; OVA, ovalbumin; PBS, phosphate-buffered saline. 

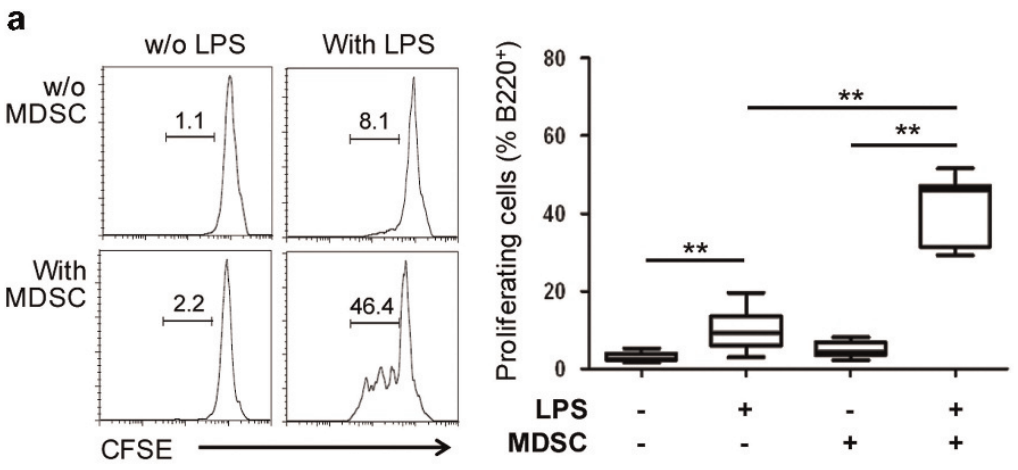

b
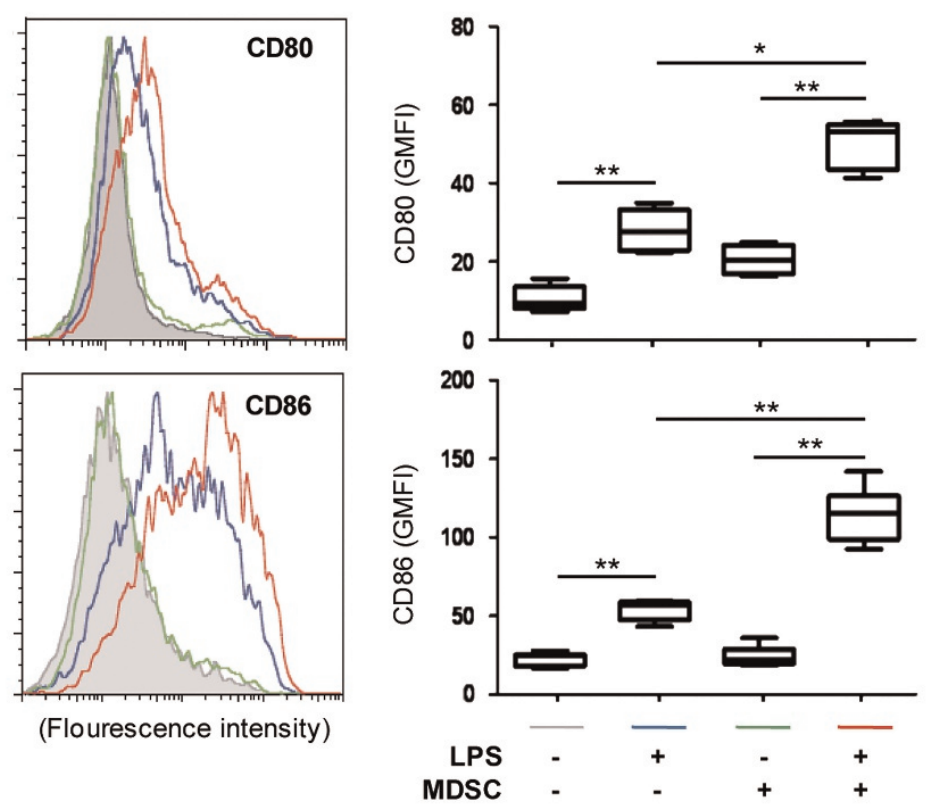
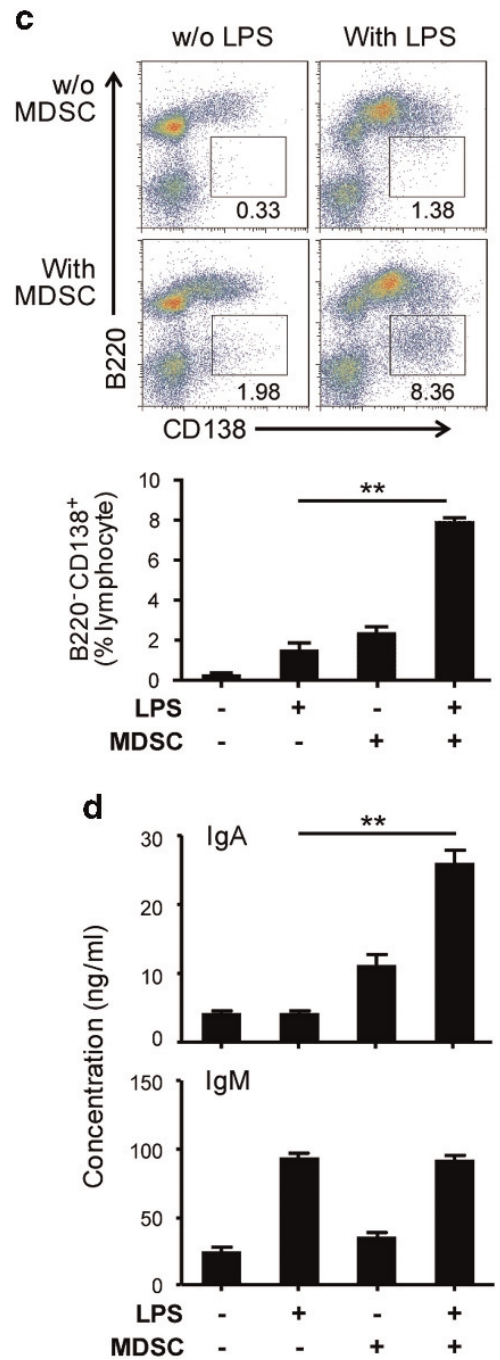

Figure 3 MDSCs activate B cells and induce IgA production in vitro. CFSE-labeled (a) and unlabeled (b-d) non-adherent spleen cells were cultured alone or with MDSCs in the presence or absence of LPS $(1 \mu \mathrm{g} / \mathrm{ml})$. (a) The $\mathrm{B}^{2} 2 \mathrm{O}^{+}$cell division was assessed by flow cytometry with a CFSE dilution after $72 \mathrm{~h}$. (b) The CD80 and CD86 levels on the B220 cells were analyzed by flow cytometry after $48 \mathrm{~h}$. (c) The B220-CD138+ plasma cell percentages within the lymphocyte population were monitored by flow cytometry after $72 \mathrm{~h}$. (d) The antibody subtype concentrations were determined from the cell culture supernatants after $72 \mathrm{~h}$ with specific ELISA. The left (a, b) and upper (c) panels show representative plots and percentages of the positive cells. The right $(\mathbf{a}, \mathbf{b})$ and lower (c) panels as well as panel $\mathbf{d}$ summarize four independent experiments with triplicate determinations. ${ }^{*} P<0.05$ and ${ }^{* *} P<0.01$, as determined with the Mann-Whitney test. CFSE, carboxyfluorescein succinimidyl ester; ELISA, enzyme-linked immunosorbent assay; Ig, immunoglobulin; MDSCs, myeloidderived suppressor cells.

IL-10 and TGF- $\beta 1$ are crucial for IgA response of B cells To analyze the impact of cell-cell contact on IgA production of $\mathrm{B}$ cells, we first tested the supernatants of our co-cultures for cytokines. The TGF- $\beta 1$, IL-10, IFN- $\gamma$ and MCP-1 levels were found to be significantly increased in co-cultures of wild-type MDSCs with non-adherent splenocytes, relative to the cultures of the individual cell types. The addition of non-adherent splenocytes to the MDSC cultures did not affect the secretion of IL- 6 and TNF (Figure 5a). Because TGF- $\beta 1$ and IL-10 are crucial for IgA production, ${ }^{22}$ IgA production was analyzed in our co-culture system following the blockade of both cytokines. Indeed, neutralization of either IL-10 or TGF- $\beta 1$ by antibodies or by inhibiting the TGF $\beta R I$ kinase with SD208 diminished the IgA levels, but not the IgM production (Figure $5 b$ ). Blockade of
TNF-related molecules, especially TNFR2 and TNF, in the wild-type MDSC and B-cell co-cultures in the presence of LPS resulted in reduced secretion of IL-10, but not of TGF- $\beta 1$ (Figure 5c). IgA production was also found to be significantly lower relative to the controls (Figure $5 \mathrm{~d}$ ). Downregulation of IL-10 in the TNFR2 ${ }^{-1-}$ MDSCs was also detected at the mRNA level (Supplementary Figure 6).

Together, these results suggest that IL- 10 and TGF- $\beta 1$ are crucial for IgA responses in B cells.

\section{DISCUSSION}

On the basis of the observation that $\operatorname{IgA}{ }^{+}$cells at the edge of the germinal centers in tumor-bearing mouse spleens were surrounded by MDSCs, we investigated the role of MDSCs 

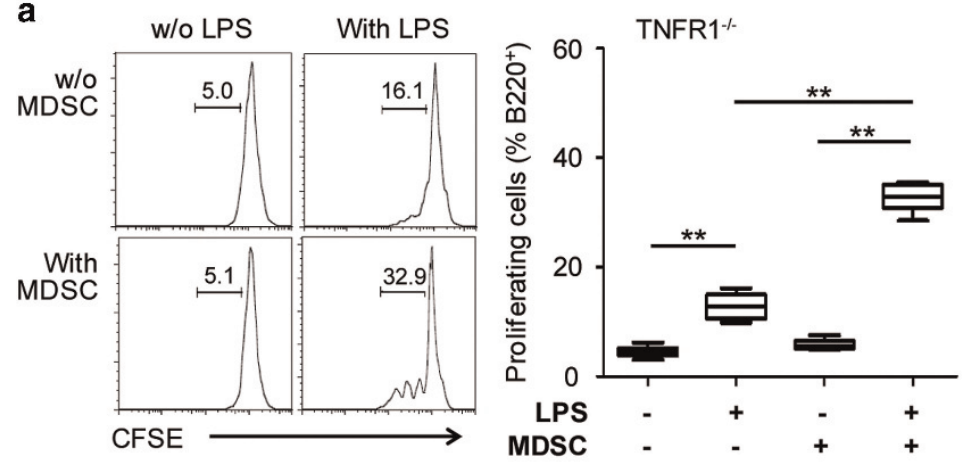

b

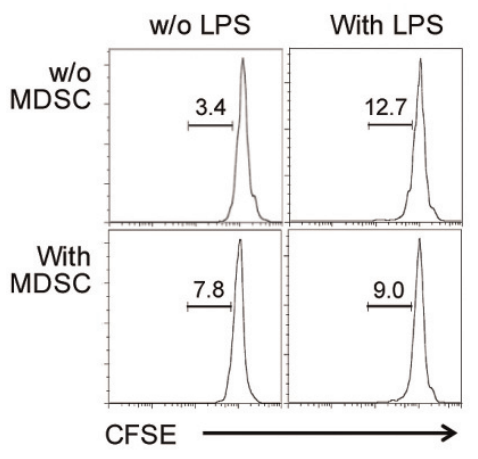

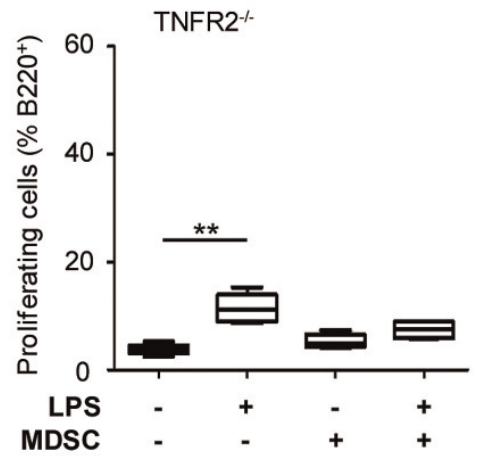

C
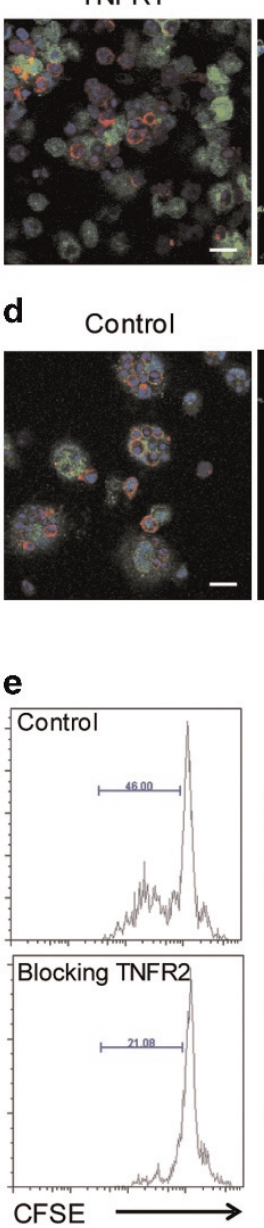

TNFR2-1-

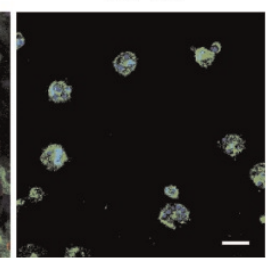

Blocking TNFR2

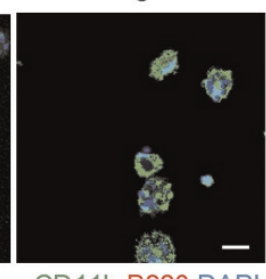

CD11b B220 DAPI

Figure 4 TNFR2 is necessary for MDSC-mediated B-cell proliferation in vitro. (a, b) CFSE-labeled non-adherent spleen cells were cultured alone or with TNFR1 $1^{-1-}(\mathbf{a})$ or TNFR2 ${ }^{-1-}$ MDSCs (b) in the presence or absence of LPS $(1 \mu \mathrm{g} / \mathrm{ml})$. The B220 cell division was assessed by flow cytometry for CFSE dilutions after $72 \mathrm{~h}$. The left panels show representative histogram plots and percentages of the divided cells. The right panels summarize three independent experiments with triplicate determinations. ${ }^{*} P<0.05$ and ${ }^{* *} P<0.01$, as determined with the Mann-Whitney test. (c, d) Non-adherent spleen cells were co-cultured with TNFR1 $1^{-/-}$or TNFR2 ${ }^{-1-}$ MDSCs (c) or with wild-type MDSCs in the presence or absence of antibodies specifically blocking TNFR2 (100 ng/ml) (d) for $72 \mathrm{~h}$. LPS (1 $\mu$ g/ml) was added into all of the cultures in $\mathbf{c}$ and $\mathbf{d}$. The adhesion of $\mathrm{B}^{220^{+}}$(red) cells and CD11 ${ }^{+}$MDSCs (green) cells was visualized by cLSM. The nuclei were counterstained with DAPI; scale bars, $20 \mu \mathrm{m}$. (e) CFSE-labeled non-adherent spleen cells were cultured with MDSCs in the presence of LPS with or without TNFR2 blockade $(100 \mathrm{ng} / \mathrm{ml})$, and the $\mathrm{B} 22 \mathrm{O}^{+}$cell division was assessed by flow cytometry as a CFSE dilution after $72 \mathrm{~h}$. The left panels show representative histogram plots and percentages of the divided cells. The right panels indicate mean values \pm s.e.m. of the percentages of the divided $\mathrm{B} 220^{+}$cells from three independent experiments with triplicate determinations. ${ }^{*} P<0.05$ and ${ }^{* *} P<0.01$, as determined with Student's $t$-test. CFSE, carboxyfluorescein succinimidyl ester; cLSM, confocal laser scanning microscope; MDSCs, myeloid-derived suppressor cells; TNFR, tumor necrosis factor receptor.

in serum IgA production. We found that the cell-cell contactdependent activation of MDSCs was mediated via TNFR2 on MDSCs and memTNF on B cells. As a result, activated MDSCs promoted splenic IgA production. Our study reveals a novel dialog between MDSCs and B cells in tumor-bearing mice.

MDSCs from various pathological conditions, such as cancer, inflammation, and autoimmune diseases, are able to suppress T-cell responses; ${ }^{4}$ however, their effects on B cells are not well established. MDSCs from mice with collagen-induced arthritis inhibit autologous B-cell proliferation and antibody production. ${ }^{23}$ MDSCs from a retrovirus infection model also counteracted B-cell responses in vitro. ${ }^{24}$ However, aluminduced myeloid cell populations are required for in vivo priming and expansion of antigen-specific B cells, as well as for optimal antibody production in mouse models, ${ }^{25}$ supporting the idea that MDSCs boost B-cell function. Similarly, we found that MDSCs from MCA205 tumor-bearing mice promoted B-cell proliferation and IgA production. As murine MDSC populations are typically heterogeneous, exhibiting various phenotypes, ${ }^{4}$ it is possible that different MDSC subsets elicit different effects on B-cell functions. However, further studies are required to address this question.

The well-studied source of IgA is gut-associated lymphoid tissue, which is responsible for the generation of IgA-secreting cells in response to commensals and pathogens, against which IgA acts as a first-line barrier. ${ }^{9}$ In our system, IgA production 
a

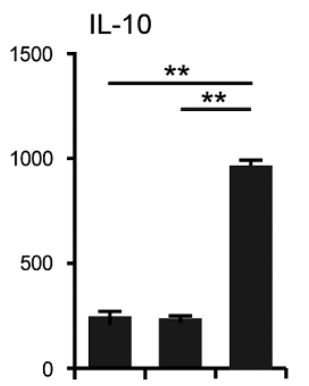

TGF- $\beta 1$

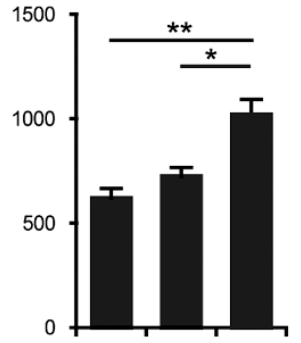

b

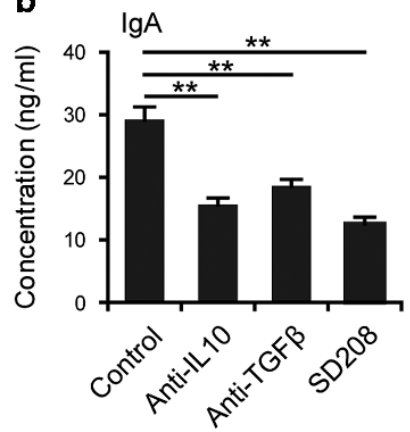

c

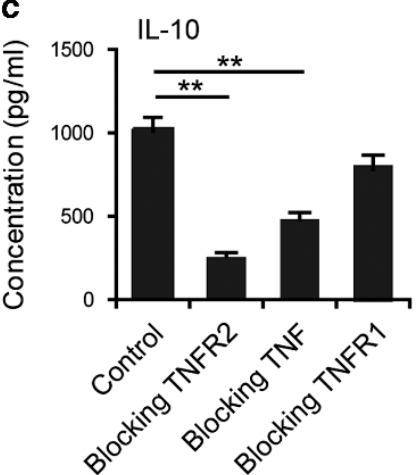

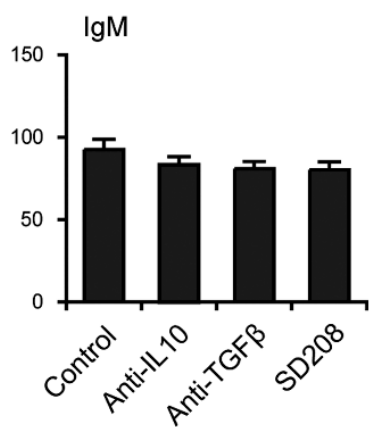

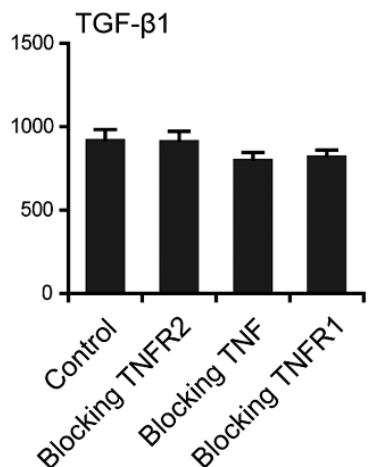

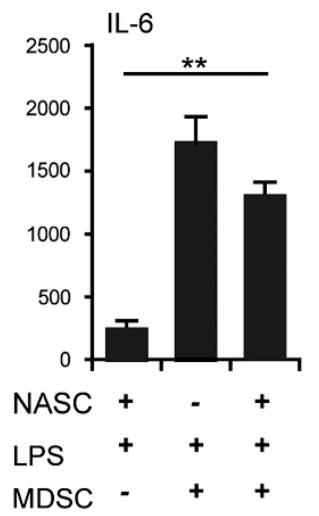
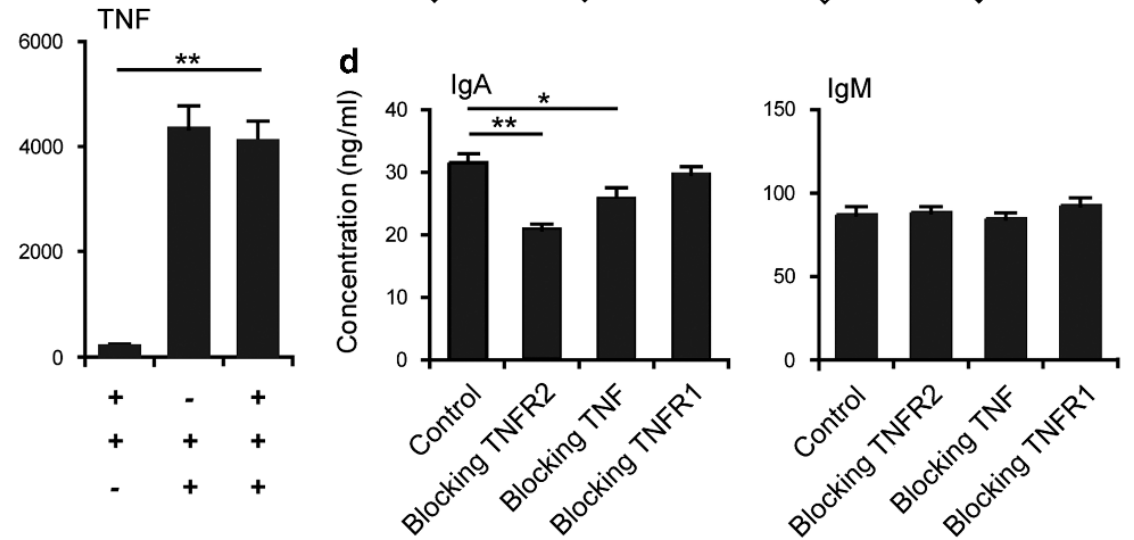

Figure 5 IgA production requires IL-10 and TGF- $\beta 1$. (a) In the presence of LPS ( $1 \mu \mathrm{g} / \mathrm{ml})$, NASC and MDSCs were cultured alone or in a co-culture for $16 \mathrm{~h}$ before the cytokines in the supernatants were determined with CBA (IL-10, IFN- $\gamma$, MCP-1, IL-6 and TNF) or with ELISA (TGF- $\beta 1)$. (b) Non-adherent spleen cells were co-cultured with MDSCs and LPS ( $1 \mu \mathrm{g} / \mathrm{ml})$ alone or in the presence of anti-IL-10 (10 ng/ml), anti-TGF- $\beta(100 \mathrm{ng} / \mathrm{ml})$ or the TGF $\beta \mathrm{RI}$ inhibitor, SD208 $(1 \mu \mathrm{M})$ for $72 \mathrm{~h}$. The IgA and IgM antibody concentrations within the supernatants were detected with specific ELISA. (c, d) Non-adherent spleen cells were co-cultured for $16 \mathrm{~h}$ or $72 \mathrm{~h}$ with MDSCs and LPS (1 $\mu$ g/ml) alone or in the presence of antibodies that specifically blocked TNFR2 (100 ng/ml), TNF (100 ng/ml) or TNFR1 (1 $\mu$ g/ml). IL-10 and TGF$\beta 1$ at $16 \mathrm{~h}$ (c) as well as IgM and IgA antibodies at $72 \mathrm{~h}(\mathbf{d})$ were detected from the supernatants with ELISA or CBA (IL-10). For a and c, the mean values \pm s.e.m. of at least 5 wells per group are shown. This experiment was repeated at least 4 times. ${ }^{*} P<0.05$ and $* * P<0.01$, as determined with Student's $t$-test. Panels $\mathbf{b}$ and $\mathbf{d}$ summarize three independent experiments with triplicate determinations. ${ }^{*} P<0.05$ and ${ }^{*} P<0.01$, as determined with the Mann-Whitney test. CBA, cytometric bead array; ELISA, enzyme-linked immunosorbent assay; Ig, immunoglobulin; IFN, interferon; IL, interleukin; MCP, monocyte chemotactic protein; MDSCs, myeloid-derived suppressor cells; NASC, non-adherent splenocytes, TGF $\beta R$ I, TGF $\beta$ receptor-1; TNF, tumor necrosis factor; TNFR, tumor necrosis factor receptor.

was detected in a co-culture system of MDSCs and nonadherent spleen cell fractions containing B cells. Currently, $B$ cells are subdivided into at least three subtypes, namely B1 cells, follicular B2 cells and marginal zone B cells. ${ }^{26}$ $\mathrm{B} 1$ cells are mainly enriched in the peritoneal and pleural cavities. ${ }^{27}$ Follicular B2 cells and marginal zone B cells constitute the majority of splenic B cells, and they are found in B-cell follicles and the marginal zone, respectively. ${ }^{28}$ By culturing purified B-cell populations, a related study reported that enhanced IgA class switching occurred in mouse splenic marginal zone B cells relative to follicular B2 cells. ${ }^{27}$ In agreement with these earlier results, we found that MDSCs were co-localized with $\mathrm{B} 220^{+}$marginal zone B cells in the spleen of tumor-bearing mice; however, little is known 
about the function of IgA from non-intestinal tissues. ${ }^{29}$ Intestinal IgA that is induced by commensals does not act as a pro-inflammatory factor; instead, it regulates intestinal homeostasis. ${ }^{30}$ IgA levels are elevated in the presence of various tumors; therefore, such changes can be used as parameters to monitor disease and/or to establish a prognosis, including IgA that is specific for an Epstein-Barr viral capsid antigen in nasopharyngeal carcinoma patients; ${ }^{31}$ IgA that is specific for Helicobacter pylori in patients with gastric cancer; ${ }^{32}$ and serum IgA in head, neck and prostatic carcinomas. ${ }^{33,34}$ IgA-deficient individuals have a higher risk for autoimmune disorders, but not for cancer development. ${ }^{35}$ This close relationship between IgA and cancer frequency prompted us to investigate the role of IgA in tumor development. As the IgA production from splenic $\mathrm{B}$ cells was increased in the presence of MDSCs, we hypothesized that the IgA produced upon stimulation by MDSCs could facilitate tumor growth by inhibiting antitumor immunity; however, its effect needs to be clearly demonstrated through further experimentation.

The role of B-cell function during tumor immunity remains under debate. On one hand, B cells impair tumor development by facilitating T-cell-mediated responses. Additionally, depletion of $\mathrm{CD} 20^{+} \mathrm{B}$ cells enhanced the tumor burden in the lungs of a B16-F10 melanoma model. ${ }^{36}$ However, syngeneic tumors progress poorly in B-cell-deficient $\mu \mathrm{MT}$ mice unless they are replenished with $\mathrm{B} 220^{+} \mathrm{B}$ cells, as a non-protective humoral immune response is induced in the presence of $\mathrm{B}$ cells. ${ }^{7}$ Additionally, it has been described that splenectomy can inhibit tumor growth in certain cases. ${ }^{37} \mathrm{IgA}^{+}$plasmocytes suppressed the antitumor immunity in a mouse prostate cancer model. ${ }^{16}$ However, several questions remain to be addressed before the mechanism of how $\mathrm{IgA}^{+}$plasmocytes suppress antitumor immunity is clear. In particular, the point of whether the suppression can be attributed to the role of $\operatorname{IgA}^{+}$plasmocytes or IgA alone needs further study. Here, we found that MDSCs in the spleen of tumor-bearing mice preferentially induced the production of IgA, rather than IgG or IgM. This result suggests that the effects of $\mathrm{B}$ cells on tumor immunity might be attributed to the Ig-subtype composition, with IgA having negative and IgG or IgM having supporting effects on immunity against tumors.

TNF signaling affects MDSC differentiation and activation on different levels. ${ }^{38,39}$ TNFR2 is a crucial factor for splenic MDSC accumulation and activation. ${ }^{3,15}$ We found that the lack of this receptor on MDSCs abrogated the ability to promote B-cell responses, whereas the lack of TNFR1 exhibited no such effect. Different from TNFR1, TNFR2 is highly regulated, resulting in low expression levels only on immune cells under physiological conditions. ${ }^{13,40}$ The ligand involved in MDSC activation via TNFR2 is memTNF, but not soluble TNF. ${ }^{15}$ In the spleen, B-cell-TNF signals are important for maintaining the structure of follicular dendritic cell clusters and germinal centers. ${ }^{41,42}$ Additionally, memTNF supports the formation of germinal centers during autoimmune inflammation. ${ }^{43}$ In agreement with these earlier results, we showed here that splenic B cells are the major source of memTNF, the ligand for
TNFR2-dependent MDSC activation. However, memTNF not only transmits signals to target cells as a ligand, but also acts as a receptor that transmits outside-to-inside (reverse) signals back to the cells after binding to its native receptors. ${ }^{44,45}$ Whether the reverse signaling is involved in IgA synthesis in $B$ cells still requires investigation.

The role of TNF in tumor immunity is complex. Previous data reported that TNF promotes antitumor responses. ${ }^{46,47}$ However, contrary evidence is becoming more and more abundant, which shows that TNF has tumor-promoting effects. ${ }^{48,49}$ The opposing effects of TNF in tumor immunity are closely related to its different temporal and spatial expression patterns. Targeting TNF is becoming a treatment option in both immune-mediated chronic inflammatory diseases and cancer. ${ }^{50,51}$ However, anti-TNF therapy is still in its early stages, ${ }^{38}$ and therefore further studies will be required to identify the precise mechanisms of this targeted therapy in different organs and immune system. Together, our study provides the first evidence that in tumor-bearing mice, MDSCs activated via TNFR2 by memTNF on B cells promote splenic IgA production, hence suggesting a potential beneficial contribution of anti-TNF therapy to treat inflammatory diseases, which may also have suppressive effects on cancer progression.

\section{CONFLICT OF INTEREST}

The authors declare no conflict of interest.

\section{ACKNOWLEDGEMENTS}

We thank Dr Claudia Berek for her critical reading of the manuscript. This work was supported by the Ministry of Science and Technology of China (2012CB917103, 2012CB934003), the National Natural Science Foundation of China (91229203) and the German Research Foundation (DFG 749-6/1 and SFB 633).

1 Youn JI, Gabrilovich DI. The biology of myeloid-derived suppressor cells: the blessing and the curse of morphological and functional heterogeneity. Eur J Immunol 2010; 40: 2969-2975.

2 Jiang J, Wang Z, Li Z, Zhang J, Wang C, Xu X et al. Early exposure of high-dose interleukin-4 to tumor stroma reverses myeloid cell-mediated T-cell suppression. Gene Ther 2010; 17: 991-999.

3 Zhao X, Rong L, Zhao X, Li X, Liu X, Deng J et al. TNF signaling drives myeloid-derived suppressor cell accumulation. J Clin Invest 2012; 122: 4094-4104.

4 Gabrilovich DI, Nagaraj S. Myeloid-derived suppressor cells as regulators of the immune system. Nat Rev Immunol 2009; 9: 162-174.

5 Monach PA, Schreiber H, Rowley DA. CD4+ and B lymphocytes in transplantation immunity. II. Augmented rejection of tumor allografts by mice lacking B cells. Transplantation 1993; 55: 1356-1361.

6 Schultz KR, Klarnet JP, Gieni RS, HayGlass KT, Greenberg PD. The role of $\mathrm{B}$ cells for in vivo $T$ cell responses to a Friend virus-induced leukemia. Science 1990; 249: 921-923.

7 Qin Z, Richter G, Schuler T, Ibe S, Cao X, Blankenstein T. B cells inhibit induction of T cell-dependent tumor immunity. Nat Med 1998; 4: 627-630.

8 de Visser KE, Eichten A, Coussens LM. Paradoxical roles of the immune system during cancer development. Nat Rev Cancer 2006; 6: 24-37.

9 Pabst $\mathrm{O}$. New concepts in the generation and functions of IgA. Nat Rev Immunol 2012; 12: 821-832. 
10 Woof JM, Kerr MA. The function of immunoglobulin A in immunity. J Pathol 2006; 208: 270-282.

11 Macpherson AJ, Gatto D, Sainsbury E, Harriman GR, Hengartner H, Zinkernagel RM. A primitive T cell-independent mechanism of intestinal mucosal IgA responses to commensal bacteria. Science 2000; 288: 2222-2226.

12 Mantovani A, Allavena P, Sica A, Balkwill F. Cancer-related inflammation. Nature 2008; 454: 436-444.

13 Fiers W. Tumor necrosis factor. Characterization at the molecular, cellular and in vivo level. FEBS Lett 1991; 285: 199-212.

14 Grell M, Douni E, Wajant H, Lohden M, Clauss M, Maxeiner B et al. The transmembrane form of tumor necrosis factor is the prime activating ligand of the $80 \mathrm{kDa}$ tumor necrosis factor receptor. Cell 1995; 83: 793-802.

15 Hu X, Li B, Li X, Zhao X, Wan L, Lin G et al. Transmembrane TNFalpha promotes suppressive activities of myeloid-derived suppressor cells via TNFR2. J Immunol 2014; 192: 1320-1331.

16 Shalapour S, Font-Burgada J, Di Caro G, Zhong Z, Sanchez-Lopez E, Dhar $\mathrm{D}$ et al. Immunosuppressive plasma cells impede T-cell-dependent immunogenic chemotherapy. Nature 2015; 521: 94-98.

17 Shu SY, Rosenberg SA. Adoptive immunotherapy of newly induced murine sarcomas. Cancer Res 1985; 45: 1657-1662.

18 Kusmartsev S, Cheng F, Yu B, Nefedova Y, Sotomayor E, Lush R et al. All-trans-retinoic acid eliminates immature myeloid cells from tumorbearing mice and improves the effect of vaccination. Cancer Res 2003; 63: 4441-4449.

19 Nefedova Y, Fishman M, Sherman S, Wang X, Beg AA, Gabrilovich DI. Mechanism of all-trans retinoic acid effect on tumor-associated myeloid-derived suppressor cells. Cancer Res 2007; 67: 11021-11028.

20 Kamata T, Nogaki F, Fagarasan S, Sakiyama T, Kobayashi I, Miyawaki $\mathrm{S}$ et al. Increased frequency of surface IgA-positive plasma cells in the intestinal lamina propria and decreased IgA excretion in hyper IgA (HIGA) mice, a murine model of IgA nephropathy with hyperserum IgA. J Immunol 2000; 165: 1387-1394.

21 Wang W, Li Q, Zhang J, Wu H, Yin Y, Ge Q et al. Hemokinin-1 activates the MAPK pathway and enhances $B$ cell proliferation and antibody production. J Immunol 2010; 184: 3590-3597.

22 Defrance T, Vanbervliet B, Briere F, Durand I, Rousset F, Banchereau J. Interleukin 10 and transforming growth factor beta cooperate to induce anti-CD40-activated naive human B cells to secrete immunoglobulin A. J Exp Med 1992; 175: 671-682.

23 Crook KR, Jin M, Weeks MF, Rampersad RR, Baldi RM, Glekas AS et al. Myeloid-derived suppressor cells regulate $T$ cell and B cell responses during autoimmune disease. J Leukoc Biol 2015; 97: 573-582.

24 Green KA, Cook WJ, Green WR. Myeloid-derived suppressor cells in murine retrovirus-induced AIDS inhibit T- and B-cell responses in vitro that are used to define the immunodeficiency. J Virol 2013; 87: 2058-2071.

25 Jordan MB, Mills DM, Kappler J, Marrack P, Cambier JC. Promotion of B cell immune responses via an alum-induced myeloid cell population. Science 2004; 304: 1808-1810.

26 Zhang X. Regulatory functions of innate-like B cells. Cell Mol Immunol 2013; 10: 113-121.

27 Kaminski DA, Stavnezer J. Enhanced IgA class switching in marginal zone and B1 B cells relative to follicular/B2 B cells. J Immunol 2006; 177: 6025-6029.

28 Baumgarth $N$. The double life of a B-1 cell: self-reactivity selects for protective effector functions. Nat Rev Immunol 2011; 11: 34-46.

29 Rosado MM, Aranburu A, Capolunghi F, Giorda E, Cascioli S, Cenci F et al. From the fetal liver to spleen and gut: the highway to natural antibody. Mucosal Immunol 2009; 2: 351-361.

30 Cerutti A, Rescigno $M$. The biology of intestinal immunoglobulin A responses. Immunity 2008; 28: 740-750.

$31 \mathrm{Ho} \mathrm{HC}, \mathrm{Ng} \mathrm{MH}$, Kwan HC. Factors affecting serum IgA antibody to Epstein-Barr viral capsid antigens in nasopharyngeal carcinoma. Br J Cancer 1978; 37: 356-362.

32 Kosunen TU, Seppala K, Sarna S, Aromaa A, Knekt P, Virtamo J et al. Association of Helicobacter pylori IgA antibodies with the risk of peptic ulcer disease and gastric cancer. World J Gastroenterol 2005; 11 : 6871-6874.

33 Deture FA, Deardourff SL, Kaufman HE, Centifanto YM. A comparison of serum immunoglobulins from patients with nonneoplastic prostates and prostatic carcinoma. J Urol 1978; 120: 435-437.

34 Baseler MW, Maxim PE, Veltri RW. Circulating IgA immune complexes in head and neck cancer, nasopharyngeal carcinoma, lung cancer, and colon cancer. Cancer 1987; 59: 1727-1731.

35 Ludvigsson JF, Neovius M, Hammarstrom L. Association between IgA deficiency \& other autoimmune conditions: a population-based matched cohort study. J Clin Immunol 2014; 34: 444-451.

36 DiLillo DJ, Yanaba K, Tedder TF. B cells are required for optimal CD4+ and $\mathrm{CD} 8+\mathrm{T}$ cell tumor immunity: therapeutic B cell depletion enhances B16 melanoma growth in mice. J Immunol 2010; 184: 4006-4016.

37 Kumashiro R, Shiraishi M, Sugimachi K, Hiramoto Y, Tamada R, Okamura $\mathrm{T}$ et al. Bidirectional effects of splenectomy on the growth of syngeneic tumor in mice. Jpn J Surg 1984; 14: 167-173.

38 Palladino MA, Bahjat FR, Theodorakis EA, Moldawer LL. Anti-TNFalpha therapies: the next generation. Nat Rev Drug Discov 2003; 2: 736-746.

39 Geissmann F, Manz MG, Jung S, Sieweke MH, Merad M, Ley K. Development of monocytes, macrophages, and dendritic cells. Science 2010; 327: 656-661.

40 Naude PJ, den Boer JA, Luiten PG, Eisel UL. Tumor necrosis factor receptor cross-talk. FEBS J 2011; 278: 888-898.

41 Pasparakis M, Alexopoulou L, Episkopou V, Kollias G. Immune and inflammatory responses in TNF alpha-deficient mice: a critical requirement for TNF alpha in the formation of primary B cell follicles, follicular dendritic cell networks and germinal centers, and in the maturation of the humoral immune response. J Exp Med 1996; 184: 1397-1411.

42 Tumanov AV, Grivennikov SI, Kruglov AA, Shebzukhov YV, Koroleva EP, Piao $Y$ et al. Cellular source and molecular form of TNF specify its distinct functions in organization of secondary lymphoid organs. Blood 2010; 116: 3456-3464.

43 Ruuls SR, Hoek RM, Ngo VN, McNeil T, Lucian LA, Janatpour MJ et al. Membrane-bound TNF supports secondary lymphoid organ structure but is subservient to secreted TNF in driving autoimmune inflammation. Immunity 2001; 15: 533-543.

44 Eissner G, Kolch W, Scheurich P. Ligands working as receptors: reverse signaling by members of the TNF superfamily enhance the plasticity of the immune system. Cytokine Growth Factor Rev 2004; 15: 353-366.

45 Horiuchi T, Mitoma H, Harashima S, Tsukamoto H, Shimoda T. Transmembrane TNF-alpha: structure, function and interaction with anti-TNF agents. Rheumatology (Oxford) 2010; 49: 1215-1228.

46 Qin Z, Kruger-Krasagakes S, Kunzendorf U, Hock H, Diamantstein T, Blankenstein T. Expression of tumor necrosis factor by different tumor cell lines results either in tumor suppression or augmented metastasis. J Exp Med 1993; 178: 355-360.

47 Zhao X, Mohaupt M, Jiang J, Liu S, Li B, Qin Z. Tumor necrosis factor receptor 2-mediated tumor suppression is nitric oxide dependent and involves angiostasis. Cancer Res 2007; 67: 4443-4450.

48 Moore RJ, Owens DM, Stamp G, Arnott C, Burke F, East N et al. Mice deficient in tumor necrosis factor-alpha are resistant to skin carcinogenesis. Nat Med 1999; 5: 828-831.

49 Scott KA, Moore RJ, Arnott CH, East N, Thompson RG, Scallon BJ et al. An anti-tumor necrosis factor-alpha antibody inhibits the development of experimental skin tumors. Mol Cancer Ther 2003; 2: 445-451.

50 Harrison ML, Obermueller E, Maisey NR, Hoare S, Edmonds K, Li NF et al. Tumor necrosis factor alpha as a new target for renal cell carcinoma: two sequential phase II trials of infliximab at standard and high dose. J Clin Oncol 2007; 25: 4542-4549.

51 Rosenblum H, Amital H. Anti-TNF therapy: safety aspects of taking the risk. Autoimmun Rev 2011; 10: 563-568.

Supplementary Information for this article can be found on the Cellular \& Molecular Immunology website (http://www.nature.com/cmi) 